\title{
Primary esophageal large T-cell lymphoma mimicking esophageal carcinoma: A case report and literature review
}

\author{
Patrick L. Wagner, MD, a,b Wayne Tam, MD, PhD, ${ }^{\mathrm{b}}$ Pauline Y. Lau, MD, ${ }^{\mathrm{c}}$ Jeffrey L. Port, MD, ${ }^{\text {a }}$ Subroto Paul, MD, ${ }^{\mathrm{a}}$ \\ Nasser K. Altorki, MD, a and Paul C. Lee, MD, ${ }^{a}$ New York, NY
}

丹 Supplemental material is available online.

W e report a rare case of primary esophageal T-cell lymphoma. Although these tumors may be difficult to distinguish clinically from more common mass lesions of the esophagus, obtaining an accurate diagnosis is vital to select an appropriate course of treatment.

\section{Clinical Summary}

A 64-year-old Chinese man, with no other significant medical history, was seen with a 6-month history of dysphagia, initially with solid food and later progressing to liquids as well. He denied hemoptysis, hematemesis, and weight loss and reported an inactive smoking history of 10 pack-years and occasional alcohol consumption. Results of physical examination were unremarkable, with no palpable lymphadenopathy, ascites, or organomegaly. Initial laboratory values, including blood cell counts, were normal.

A barium swallow suggested external compression of the esophagus. On endoscopy, a polypoid necrotic mass was seen just distal to the upper esophageal sphincter, with associated luminal narrowing (Figure 1, A). Endoscopic ultrasonography demonstrated a fullthickness anechoic lesion. Computed tomographic imagery was notable for thickening of the proximal thoracic esophagus and subcentimeter mediastinal lymph nodes (Figure E1). Positron emission tomography revealed marked fluorodeoxyglucose avidity in the esophageal mass.

Initial attempts at biopsy yielded nondiagnostic material consisting mainly of necrotic debris. Rigid esophagoscopy was used to obtain an adequate biopsy sample, which consisted of an atypical infiltrate of large lymphocytes (Figure 2, A), demonstrated by immunohistochemical staining to be T cells with loss of CD5 expression.

From the Departments of Cardiothoracic Surgery, ${ }^{a}$ and Pathology and Laboratory Medicine, ${ }^{\mathrm{b}}$ New York Presbyterian Hospital/Weill Cornell Medical Center, and the Department of Hematology/Oncology, New York Hospital Queens, ${ }^{c}$ New York, NY.

Received for publication Nov 13, 2007; accepted for publication Dec 16, 2007.

Address for reprints: Patrick L. Wagner, MD, New York-Presbyterian Hospital/Weill Cornell Medical Center, Starr-1036, 525 E 68th St, New York, NY 10021 (E-mail: plw9001@nyp.org).

J Thorac Cardiovasc Surg 2008;135:957-8

$0022-5223 / \$ 34.00$

Copyright (C) 2008 by The American Association for Thoracic Surgery

doi:10.1016/j.jtcvs.2007.12.010
Analysis for T-cell receptor rearrangement confirmed the presence of a monoclonal population, and the lesion was classified as a peripheral T-cell lymphoma of the large cell type.

After three cycles of chemotherapy with ifosfamide, methotrexate, etoposide, and prednisone, a 1.4-cm fluorodeoxyglucose-avid nodule was found in the posterolateral left lung base (Figure 1, B). Wedge resection was performed, and histologic examination revealed the presence of large, transformed lymphocytes (Figure 2, $B)$. Flow cytometry distinguished a T-cell population with aberrant loss of surface CD3 and CD5. A clonal T-cell population related to the esophageal tumor was demonstrated by gene rearrangement analysis, consistent with pulmonary involvement by the primary esophageal lymphoma.

Chemotherapy was administered for six additional cycles with rituximab, cyclophosphamide, doxorubicin, vincristine, and prednisone, after which the patient had no evidence of disease. He underwent consolidation with high-dose chemotherapy with autologous stem cell support, a regimen shown to improve survival of patients with aggressive peripheral T-cell lymphomas. ${ }^{1}$ He currently remains without evidence of disease 10 months after the initial diagnosis and 6 months after the lung resection.

\section{Discussion}

The esophagus is extremely rare as a primary site of lymphoma. ${ }^{2}$ Most primary esophageal lymphomas arise in patients older than 50 years, ${ }^{3}$ and most patients have dysphagia and weight loss, although some have hoarseness and in rare cases esophageal perforation or tracheoesophageal fistula. ${ }^{4,5}$ Tumors may arise in the proximal or distal esophagus, appearing grossly as ulcerated polypoid or circumferential lesions, and may mimic esophageal carcinoma. In many cases, multiple biopsies have been required to obtain sufficient tissue for diagnosis.

Most reported primary esophageal lymphomas have been large cell lymphomas of the B-cell type. Extranodal marginal zone Bcell lymphomas, Hodgkin lymphomas, and plasma cell neoplasms have also been reported. ${ }^{2, \mathrm{E} 1-\mathrm{E} 4}$ Only three primary esophageal Tcell lymphomas have been documented in the literature, 2 of which were of the large-cell type., ${ }^{2,3}$ The age range for these other 3 patients was 17 to 34 years, whereas our patient was in his seventh decade. The previous cases involved the lower esophagus, in contrast to the upper esophageal location in our case. Survival of these previously reported patients ranged from 6 to 14 months after diagnosis. No standard optimal treatment regimen exists for esophageal lymphomas, although radiation and chemotherapy with regimens including cyclophosphamide, doxorubicin, vincristine, and prednisone have been used. Presumably, the prognosis depends on the stage and subtype of lymphoma and its response to treatment.

In this case, the appearance of a lung lesion after initial chemotherapy for lymphoma limited the differential diagnosis to 

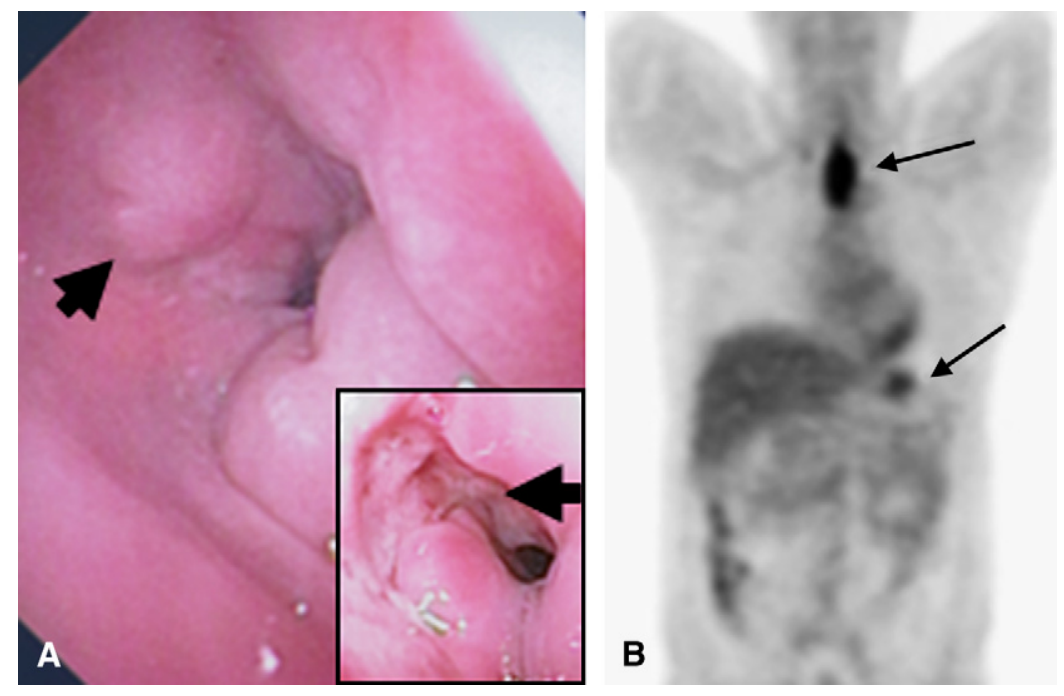

Figure 1. A, Endoscopic photograph of mass lesion (arrow) and adjacent area of ulceration (arrow, inset). B, Positron emission tomographic scan with fluorodeoxyglucose-avid lesions in esophagus and left lower lung field (arrows).
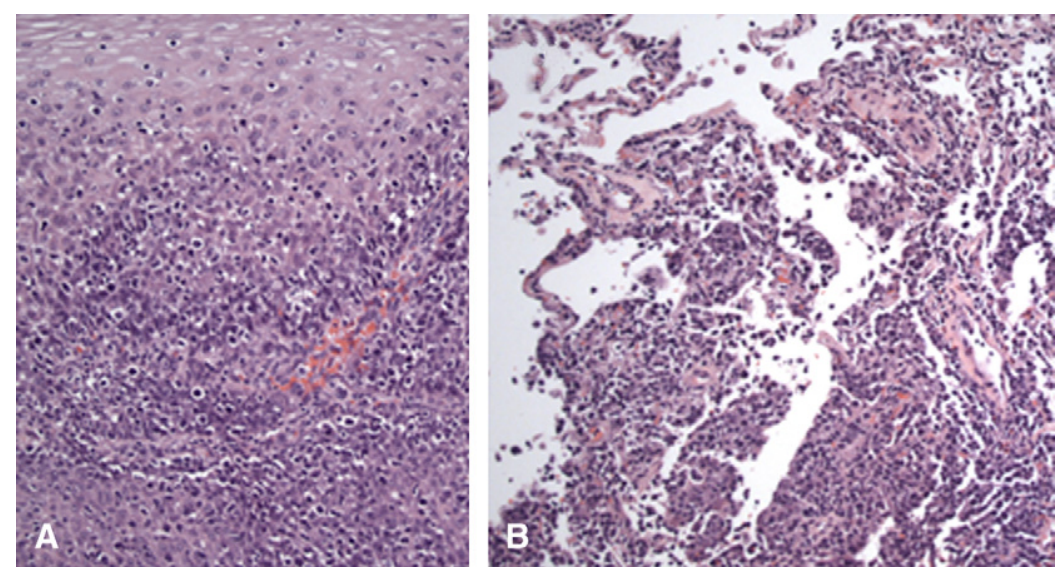

Figure 2. A, Esophageal involvement by T-cell lymphoma; overlying squamous mucosa is apparent in upper half of image. B, Interstitial pulmonary infiltrate composed of malignant T-cells; note preserved alveolar architecture on upper left of field.

pulmonary involvement by lymphoma, an infectious complication of treatment, or primary lung carcinoma. Had the lung lesion been synchronous with a constricting esophageal mass, an esophageal carcinoma with pulmonary metastases would have been favored in the differential diagnosis. This case underscores the importance of a methodical diagnostic workup, because the therapeutic options differ drastically among the entities in the differential diagnosis.

In summary, the esophagus is a rare primary site of lymphoma. Primary esophageal lymphomas may mimic carcinoma clinically and in gross appearance, and it is characteristically difficult to obtain sufficient tissue for diagnosis in the initial biopsies of these lesions. In clinical settings suggestive of lymphoma, intraoperative pathologic examination of a biopsy sample should be undertaken to ensure that sufficient material is obtained for histologic, immunophenotypic, and molecular analyses for accurate classification of these biologically diverse lesions.

\section{References}

1. Rodríguez J, Conde E, Gutiérrez A, Arranz R, León A, Marín J, et al. The results of consolidation with autologous stem-cell transplantation in patients with peripheral T-cell lymphoma (PTCL) in first complete remission: the Spanish Lymphoma and Autologous Transplantation Group experience. Ann Oncol. 2007;18:652-7.

2. Chadha KS, Hernandez-Ilizaliturri FJ, Javle M. Primary esophageal lymphoma: case series and review of the literature. Dig Dis Sci. 2006; 51:77-83.

3. Bolondi L, De Giorgio R, Santi V, Paparo GF, Pileri S, Di Febo G, et al. Primary non-Hodgkin's T-cell lymphoma of the esophagus. A case with peculiar endoscopic ultrasonographic pattern. Dig Dis Sci. 1990;35: 1426-30.

4. Kirsch HL, Cronin DW, Stein GN, Latour F, Herrera AF. Esophageal perforation. An unusual presentation of esophageal lymphoma. Dig Dis Sci. 1983;28:371-4.

5. Williams MR, Chidambaram M, Salama FD, Ansell ID. Tracheooesophageal fistula due to primary lymphoma of the oesophagus. $J R$ Coll Surg Edinb. 1984;29:60-1. 


\section{E-References}

E1. Chetty R, Bramdev A, Reddy AD. Primary extramedullary plasmacytoma of the esophagus. Ann Diagn Pathol. 2003;7:174-9.

E2. Coppens E, El Nakadi I, Nagy N, Zalcman M. Primary Hodgkin's lymphoma of the esophagus. AJR Am J Roentgenol. 2003;180:1335-7.

E3. Miyazaki T, Kato H, Masuda N, Nakajima M, Manda R, Fukuchi M, et al. Mucosa-associated lymphoid tissue lymphoma of the esophagus: case report and review of the literature. Hepatogastroenterology. 2004;51:750-3.

E4. Pehlivan Y, Sevinc A, Sari I, Gulsen MT, Buyukberber M, Kalender $\mathrm{ME}$, et al. An interesting cause of esophageal ulcer etiology: multiple myeloma of $\operatorname{IgG}$ kappa subtype. World $J$ Gastroenterol. 2006;12:2305-7.
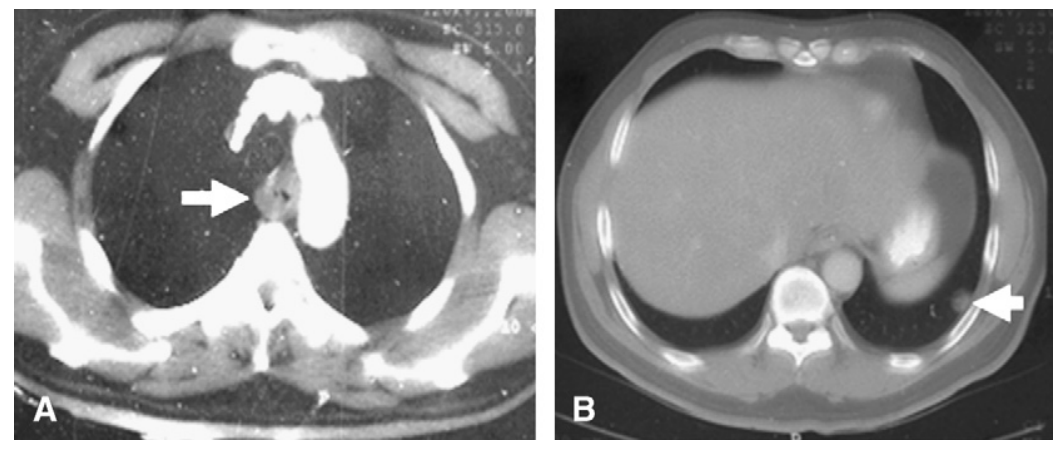

Figure E1. A, Computed tomographic scan with esophageal thickening (arrow) at level of aortic arch. B, Computed tomographic scan shows peripheral lung nodule in posterior left lower lobe (arrow). 